\title{
Differential effect of detergents on the alkaline denaturation of haemoglobin in maternal and fetal blood, with particular reference to Triton X-100
}

\author{
CG DUCK-CHONG
}

From the Department of Histology and Embryology, University of Sydney, Sydney, NSW, Australia 2006

SUMMARY In this investigation, the alkaline denaturation of haemoglobin in the blood of pregnant women and in cord blood obtained from newborn infants was followed by measuring the increase in absorbance at $375 \mathrm{~nm}$. As expected, in the absence of detergent, the haemoglobin of cord blood was much more resistant to alkaline denaturation than that of maternal blood. However, in the presence of Triton X-100, a non-ionic detergent, the sensitivity of fetal haemoglobin to alkali was comparable to that of adult haemoglobin. Similar results were obtained using the non-ionic detergents, Brij-35, Tween 80 and Nonidet P40, but the anionic detergent, sodium deoxycholate, was apparently without effect. These findings form the basis of a rapid and sensitive method for discriminating between maternal and fetal blood in biological specimens.

In the presence of alkali, adult and fetal haemoglobin are both denatured yielding alkaline hematin. ${ }^{1}$ However, fetal haemoglobin is much more resistant to alkaline denaturation than adult haemoglobin, and this difference forms the basis of classical methods for determining the relative proportions of fetal and adult haemoglobin in blood. ${ }^{1}$ At $11-12$ wk gestation, all the haemoglobin in the blood of the fetus is of the alkali-resistant fetal type. ${ }^{2}$ Blood collected from the umbilical cord at the time of delivery of the infant also contains a substantial proportion of fetal haemoglobin. ${ }^{1}$ At 28-34 wk gestation, the fetal haemoglobin content is consistently about $90 \%,{ }^{23}$ while a mean value of about $75 \%$ fetal haemoglobin, with individual values ranging from 50 to $88 \%$, has been reported for cord blood collected at term. ${ }^{24}$ In contrast, virtually all the haemoglobin in normal adult blood is alkalisensitive. ${ }^{5}$

In this paper, differences in the effect of detergents on the alkaline denaturation of haemoglobin in maternal and cord blood are described. This investigation was prompted by our requirement for a rapid and sensitive method for determining whether blood, present as a contaminant in some samples of amniotic fluid used for the evaluation of fetal lung maturity, ${ }^{6}$ is of maternal or fetal origin.

Accepted for publication 10 February 1983

\section{Material and methods}

Blood was collected, in heparinised tubes, from pregnant women near term and from the umbilical cord of both term and preterm newborn infants. Amniotic fluid was obtained by trans-abdominal amniocentesis as part of routine management of complicated pregnancies.

The rate of denaturation of haemoglobin in the presence of alkali was determined as follows: blood was diluted 1/10 with normal saline before use. The reaction mixture contained diluted blood $(50 \mu \mathrm{l}$, unless otherwise specified) and $\mathrm{Na}_{2} \mathrm{CO}_{3}(0 \cdot 1 \mathrm{~g} / \mathrm{l})$ to a final volume of $3 \mathrm{ml}$. After measuring the initial absorbance at $375 \mathrm{~nm}, 12-25 \mu$ l standardised 5 $\mathrm{mol} / \mathrm{l} \mathrm{NaOH}$ was added with rapid mixing and the absorbance was recorded for a further $5 \mathrm{~min}$. A Pye Unicam SP8-100 Spectrophotometer was used and all reactions were routinely carried out at $25^{\circ} \mathrm{C}$.

Appropriate volumes of solutions of the following detergents $(20 \mathrm{~g} / 1$, unless otherwise specified) were added to the reaction mixture, before or after the addition of $\mathrm{NaOH}$, as required: Triton X-100 (Rohm and Haas), sodium deoxycholate (E Merck), sodium dodecyl sulphate and Brij-35 (Sigma), Tween 80 (Chemical Materials), Nonidet P40 (Shell Chemicals) and cetyltrimethylammonium bromide (British Drug Houses).

Total haemoglobin was determined by the cyanmethaemoglobin method (Sigma). 
OPTIMISED PROCEDURE FOR DISCRIMINATING

BETWEEN MATERNAL AND FETAL BLOOD

Follow the procedure described above, using $25 \mu \mathrm{l} 5$ $\mathrm{mol} / \mathrm{l} \mathrm{NaOH}$. Measure the absorbance at $375 \mathrm{~nm}$ for $1 \mathrm{~min}$ after the addition of $\mathrm{NaOH}$, then add $25 \mu \mathrm{l}$ Triton X-100 (40 g/l) with immediate thorough mixing and measure the absorbance for a further $2 \mathrm{~min}$.

\section{Results}

Denaturation of haemoglobin by $\mathrm{NaOH}$ was accompanied by a marked increase in absorbance between 340 and $390 \mathrm{~nm}$. The maximum change in absorbance occurred at $372 \mathrm{~nm}$ for both maternal and cord blood, in the absence of detergent, and at $377 \mathrm{~nm}$ in the presence of Triton X-100.

In this investigation, assay conditions were deliberately chosen to highlight the well-known difference in the effect of alkali on haemoglobin in maternal and cord blood, in the absence of detergent (Fig. 1). In the presence of $40 \mathrm{mmol} / \mathrm{l} \mathrm{NaOH}$, the denaturation of haemoglobin in maternal blood was complete within $1 \mathrm{~min}$ (Fig. 1b), whereas for cord blood, the reaction took about $2 \mathrm{~h}$ to approach completion (data not shown). However, when Triton $\mathrm{X}-100$ was included in the reaction mixture, the difference in the sensitivity of the haemoglobin in maternal and cord blood to alkali was largely abolished (Fig. 1); haemoglobin from both sources was denatured rapidly, yielding approximately the same change in absorbance per milligram of haemoglobin in each case.
The effect of varying the concentration of Triton $\mathrm{X}-100$ in the reaction mixture is shown in Fig. 2, which also serves to illustrate the between-sample reproducibility of the phenomenon.

Other non-ionic detergents tested, Brij-35, Tween 80 and Nonidet P40, also behaved like Triton X-100 in that they tended to abolish the difference in the response of maternal and cord blood to alkali, the least effective (on a weight for weight basis) being Tween 80 (Table 1).

In contrast, sodium deoxycholate, a naturallyoccurring anionic detergent, appeared to be without effect (Table 1). However, the addition of another anionic detergent, sodium dodecyl sulphate, to either cord or maternal blood in itself caused a time-dependent increase in absorbance, with a subsequent very rapid increase on the addition of $\mathrm{NaOH}$ (data not shown). The cationic detergent, cetyltrimethylammonium bromide, appeared to cause immediate denaturation of haemoglobin in both maternal and cord blood in the absence of $\mathrm{NaOH}$.

The overall result was the same, whether Triton $\mathrm{X}-100$ was added before the alkali or one minute later (Fig. 3). In this experiment, for samples treated with Triton X-100 after the alkali (Fig. 3, solid lines), the procedure was identical to that described as the "Optimised procedure" in the Material and methods section. Under these conditions, only a short reaction time is required to give good discrimination between maternal and cord blood.

In the optimised procedure, the results were only

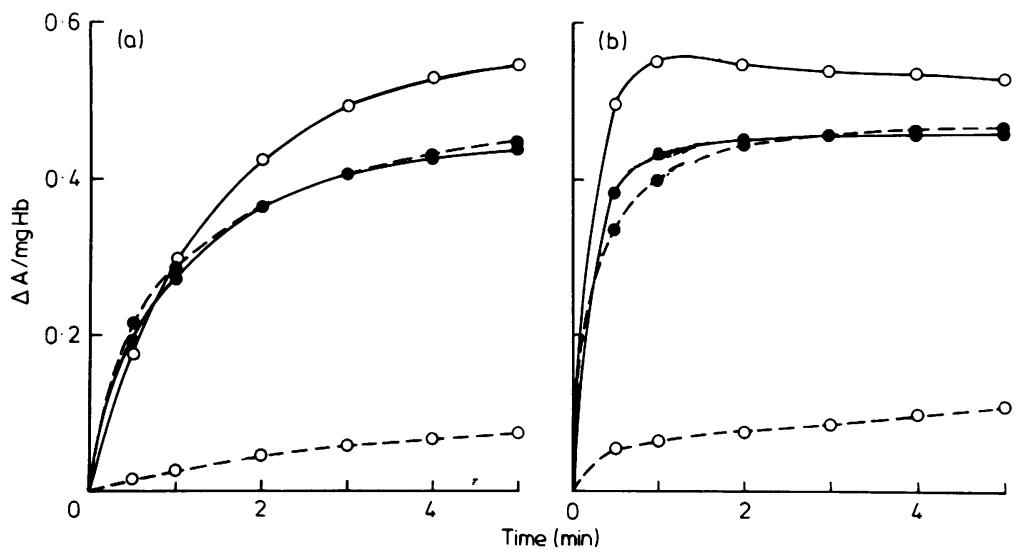

Fig. 1 Effect of Triton $X-100$ on the denaturation of haemoglobin by alkali. $\mathrm{NaOH}$ was added at zero time to reaction mixtures containing maternal blood (solid lines) or cord blood (broken lines) and the resulting change in absorbance at $375 \mathrm{~nm}(\triangle A)$ was measured. The final concentration of $\mathrm{NaOH}$ was $20 \mathrm{mmol} / \mathrm{l}$ (a) or $40 \mathrm{mmol} / \mathrm{l}$ (b). The reaction was carried out in the absence (O) or presence (O) of Triton $X-100,0 \cdot 3 \mathrm{~g} / \mathrm{l}$ final concentration. 


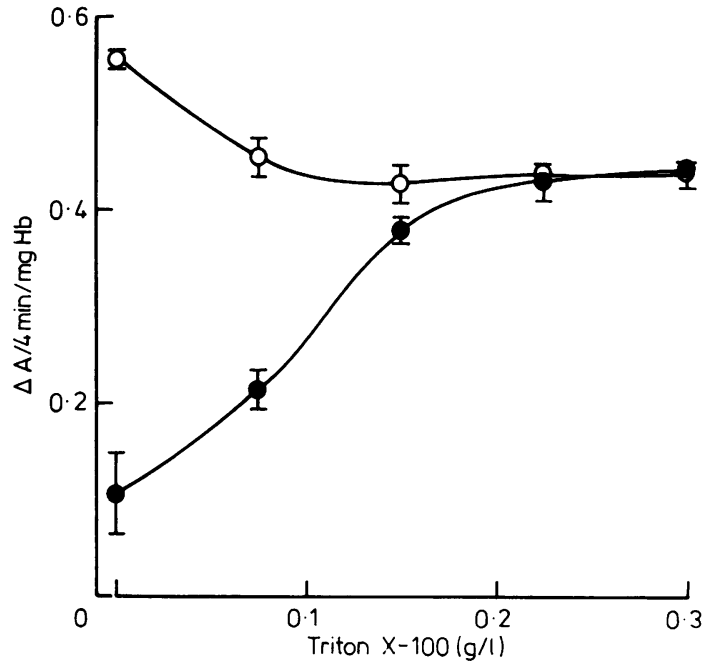

Fig. 2 Effect of varying Triton $X-100$ on the change in absorbance measured 4 min after the addition of $\mathrm{NaOH}(30$ mmolll, final concentration). Each point represents the mean value $( \pm S D)$ for three samples of cord blood $(\bullet)$, one collected at $33 w k$ and two at $40 w k$ gestation, and three samples of maternal blood (O).

slightly affected by varying the concentration of blood; the shape of the curve given by haemoglobin in maternal blood was always distinctly different from that in cord blood, as indicated by the ratio of the absorbances at $3 \mathrm{~min}$ and $1 \mathrm{~min}$ (Table 2). Varying the temperature of the assay from 20 to $30^{\circ} \mathrm{C}$ or including $200 \mu \mathrm{l}$ of blood-free amniotic fluid in the reaction mixture also had a negligible effect on the results (data not shown). The present procedure is
Table 1 Comparison of the effects of various detergents

\begin{tabular}{|c|c|c|c|c|}
\hline \multirow[t]{3}{*}{ Detergent ${ }^{*}$} & \multicolumn{4}{|c|}{ Change in absorbance/mg $\mathrm{Hb} \dagger$} \\
\hline & \multicolumn{2}{|c|}{ Maternal blood } & \multicolumn{2}{|c|}{ Cord blood } \\
\hline & $1 \min$ & $4 \min$ & $1 \min$ & $4 \mathrm{~min}$ \\
\hline $\begin{array}{l}\text { None } \\
\text { Triton X-100 } \\
\text { Brij-35 } \\
\text { Tween } 80 \\
\text { Nonidet P40 } \\
\text { Deoxycholate }\end{array}$ & $\begin{array}{l}0.55 \\
0.42 \\
0.40 \\
0.45 \\
0.43 \\
0.54\end{array}$ & $\begin{array}{l}0.53 \\
0.44 \\
0.42 \\
0.46 \\
0.44 \\
0.52\end{array}$ & $\begin{array}{l}0.07 \\
0.37 \\
0.37 \\
0.16 \\
0.42 \\
0.07\end{array}$ & $\begin{array}{l}0.11 \\
0.45 \\
0.43 \\
0 \cdot 28 \\
0 \cdot 46 \\
0 \cdot 11\end{array}$ \\
\hline
\end{tabular}

*Detergent or distilled water $(30 \mu \mathrm{l})$ was added to the reaction mixture before measuring the initial absorbance.

$\uparrow \mathrm{NaOH}$ was added at zero time (final concentration, $40 \mathrm{mmol} / \mathrm{l}$ ).

Table 2 Effect of varying blood concentration on the response of maternal and cord blood to $\mathrm{NaOH}$ and Triton $X-100$

\begin{tabular}{|c|c|c|c|c|}
\hline \multirow{3}{*}{$\begin{array}{l}\text { Volume of } \\
\text { dil blood } \\
(\mu l)\end{array}$} & \multicolumn{4}{|c|}{ Change in absorbance/mg $\mathrm{Hb}^{*}$} \\
\hline & \multicolumn{2}{|c|}{ Maternal blood } & \multicolumn{2}{|c|}{ Cord blood } \\
\hline & $1 \mathrm{~min}$ & $\begin{array}{l}3 \mathrm{~min} / \\
1 \mathrm{~min}\end{array}$ & $1 \min$ & $\begin{array}{l}3 \mathrm{~min} / \\
1 \mathrm{~min}\end{array}$ \\
\hline $\begin{array}{r}25 \\
50 \\
75 \\
100\end{array}$ & $\begin{array}{l}0.55 \\
0.52 \\
0.49 \\
0.46\end{array}$ & $\begin{array}{l}0.75 \\
0.79 \\
0.82 \\
0.85\end{array}$ & $\begin{array}{l}0.06 \\
0.06 \\
0.05 \\
0.05\end{array}$ & $\begin{array}{l}6 \cdot 7 \\
7 \cdot 1 \\
7 \cdot 6 \\
7 \cdot 8\end{array}$ \\
\hline
\end{tabular}

*The reaction was carried out according to the optimised procedure (see Material and methods). The final concentration of blood was 0.8-3.3 $\mathrm{ml} / 1$.

therefore relatively independent of temperature, within the limits prevailing in most laboratories, and can be used to assess blood-stained samples of amniotic fluid.

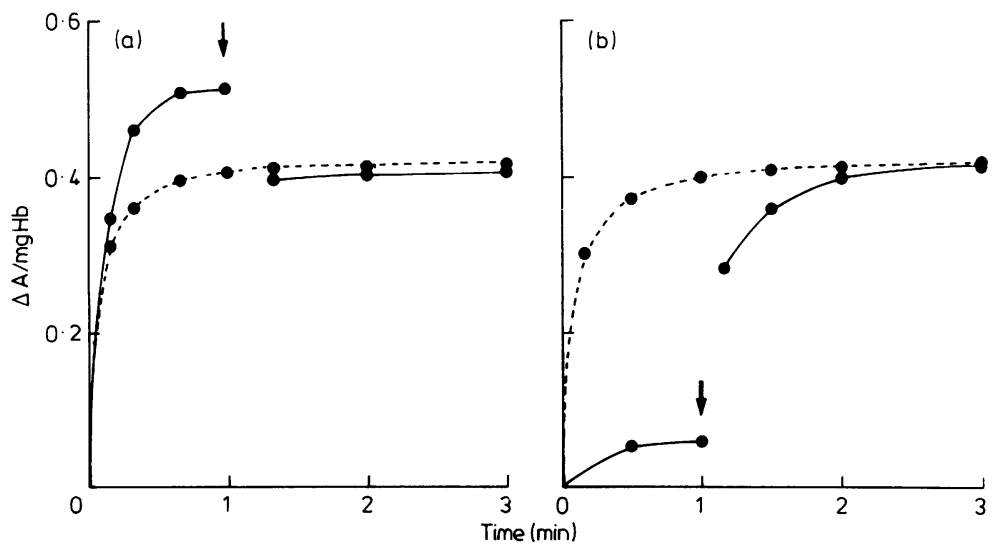

Fig. 3 Effect on the denaturation of haemoglobin of adding Triton X-100 before or after the alkali. The reaction mixture contained (a) maternal blood or (b) cord blood (33 wk gestation); $25 \mu l \mathrm{NaOH}$ was added at zero time and $25 \mu l$ Triton X-100 (40 $\mathrm{g} / \mathrm{l})$ was added either before (broken lines), or 1 min after the $\mathrm{NaOH}$ with immediate mixing (solid lines). 


\section{Discussion}

In other investigations in which the conversion of haemoglobin to alkaline hematin has been followed by direct spectrophotometric analysis, the increase in absorbance at $630 \mathrm{~nm}$ or the decrease in absorbance at 540-580 $\mathrm{nm}$ has been measured. ${ }^{1}$ Measuring the corresponding increase in absorbance at 375 $\mathrm{nm}$ gives a 7 - or $3 \cdot 5$-fold increase in sensitivity, compared with measuring at 630 or $540 \mathrm{~nm}$, respectively.

The shape of the curve given by either maternal or cord blood in response to the consecutive addition of alkali and Triton X-100 (as in the optimised procedure) is quite distinctive and the difference between cord and maternal blood is obvious within 2 min of adding the alkali (Fig. 3). Under these conditions, the increase in absorbance during the first minute (that is, in the absence of detergent) presumably represents rapid denaturation of adult haemoglobin with a variable, but usually small, contribution due to the slow denaturation of any fetal haemoglobin in the sample. On the addition of Triton X-100, the observed absorbance change presumably represents the net effect of an increase in absorbance, due to the augmentation of denaturation of any fetal haemoglobin in the sample, and a decrease in absorbance due to the interaction of the detergent with the denatured haemoglobin.

Using the optimised procedure described in this paper, it is not necessary to know the haemoglobin content of the sample in order to distinguish maternal from fetal blood. In contrast, in the absence of detergent, discrimination between maternal and cord blood is not always possible unless the change in absorbance is related back to the haemoglobin content of the sample or the reaction is allowed to proceed for a long time. For example, in Fig. 1, the difference in the curves given by maternal and cord blood in the absence of detergent is quite obvious within $5 \mathrm{~min}$, but this is largely due to the fact that absorbance changes have been expressed per mg haemoglobin. This feature of the method is especially important when haemoglobin concentrations are low, a frequent occurrence in our laboratory where blood in $160 \mu$ l samples of lightlycontaminated amniotic fluid is assessed routinely. Using the optimised procedure, clearcut discrimination between blood of fetal and maternal origin is possible even when the reaction mixture contains as little as $0.1 \mathrm{ml}$ blood per litre, giving an overall absorbance change at $3 \mathrm{~min}$ of about $0 \cdot 02$.

While the proportion of fetal haemoglobin in cord blood is generally high, it may be as low as $50 \%$ in some infants delivered at term. ${ }^{24}$ On the assumption that the samples of maternal and preterm cord blood used to derive the data in Table 2 contained $100 \%$ adult haemoglobin and $10 \%$ adult- $90 \%$ fetal haemoglobin, respectively, ${ }^{2-4}$ it can be calculated that a sample of blood containing $50 \%$ fetal-50\% adult haemoglobin would give a $3 \mathrm{~min} / 1 \mathrm{~min}$ absorbance ratio of about $1 \cdot 5$, using the optimised procedure. This is appreciably higher than the $3 \mathrm{~min} / 1 \mathrm{~min}$ ratio given by maternal blood (Table 2 ). Therefore the present method can be used to determine whether blood present in an amniotic fluid sample is of fetal or maternal origin, even when the fetal blood contains a minimal proportion of fetal haemoglobin.

The present procedure meets our need for a rapid, simple and sensitive method for assessing blood in amniotic fluid and, for this specific application, is preferable to existing methods. These include alkali-denaturation methods involving spectrophotometry with or without precipitation of the alkaline hematin with ammonium sulphate ${ }^{15}$ and histological methods-for example, Kleihauer et al. ${ }^{7}$ More sophisticated techniques, also available, include electrophoresis, radial immunodiffusion and high performance liquid chromatography. The present method offers a simple alternative to existing methods in any application which requires only discrimination between blood of fetal or maternal origin. It is especially useful when only a small amount of blood is present in the sample. With further development, this approach could also be used to obtain more quantitative information about the relative proportions of adult and fetal haemoglobin present in the blood.

The author is indebted to Dr D Henderson-Smart and the obstetric staff at King George V Hospital, Camperdown, NSW, for supplying samples of maternal and cord blood and amniotic fluid.

This project was supported by grants from the National Health and Medical Research Council of Australia and the Utah Foundation.

\section{References}

${ }^{1}$ White JC, Beavan GH. A review of the varieties of human haemoglobin in health and disease. J Clin Pathol 1954;7:175-200.

${ }^{2}$ Walker J, Turnbull EPN. Haemoglobin and red cells in the human foetus. III Foetal and adult haemoglobin. Arch Dis Child 1955;30:111-6.

${ }^{3}$ Fraser ID, Raper AB. Observations on the change from fetal to adult erythropoiesis. Arch Dis Child 1962;37:289-96.

4 Brody S. Foetal type haemoglobin in the blood of the newborn. Lancet 1959;i:520-1.

s Singer K, Chernoff AI, Singer L. Studies on abnormal haemoglobins; their demonstration in sickle cell anemia and other haematologic disorders by means of alkali denaturation. Blood 1951;6:413-28. 
- Duck-Chong CG, Henderson-Smart DJ, Gupta JM, Hensley WJ. Measurement of "lamellar body phospholipid" in amniotic fluid as a method of assessing fetal lung maturity. Clin Chem 1981;27:1851-5.

${ }^{7}$ Kleihauer E, Braun H, Betke K. Demonstration von fetalem
Hamoglobin in den Erythrocyten eines Blutausstrichs. Klin Wochenschr 1957;35:637-8.

Requests for reprints to: Dr CG Duck-Chong, Department of Histology and Embryology, University of Sydney, Sydney, NSW, Australia 2006. 